\title{
A Study on the Use of Solid-Oxide Fuel Cells for Increased Power Generation on Small Aircraft
}

\author{
Brandon L. Litherland*, Nicholas K. Borer ${ }^{\dagger}$, and Steven C. Geuther ${ }^{\ddagger}$ \\ NASA Langley Research Center, Hampton, VA, 23681, U.S.A.
}

\begin{abstract}
A growing demand for higher-power electrical equipment on aircraft is driving the exploration of alternative electrical power generation devices. "Hybrid-electric" aircraft architectures that leverage multiple or alternative power sources are also becoming more popular with rising concerns over efficiency. Fuel cells are particularly interesting as auxiliary or secondary electrical power generation devices, due to their relative efficiency and longevity, and could be used as a "power pod" for vehicles without enough on-board electrical generation capability. This paper examines the feasibility and potential value of using an externally-mounted, hybridelectric, solid-oxide fuel cell (SOFC) power system on a Class IV unmanned aerial vehicle (UAV) for the purpose of power generation in excess of the baseline electrical load. Moreover, the paper will demonstrate that a SOFC auxiliary power unit (APU) provides significant value to an aircraft by producing a relatively large amount of additional electrical power for a relatively low initial investment when compared to producing additional power by scaling the engine.
\end{abstract}

Wing Taper Ratio

\section{Nomenclature}

Wing Aspect Ratio

$b$

Wingspan

$f \quad$ Flat Plate Drag

$P_{\text {out }}$

Total System Output Power

$P_{\text {Sp }}$ SOFC

SOFC Power Density

$Q$

Interfence Factor

S

Wing Planform Area

$S_{\text {wet }}$

Component Wetted Surface Area

$W_{S O F C}$

SOFC Weight

$\frac{l}{d}$

Body Length-to-Diameter Ratio

$\frac{t}{c}$

$A_{\text {sec }}$

Wing Thickness-to-Chord Ratio

$C_{f}$

Pod Cross-Section Area

FF

Friction Coefficient

$F R$

Form Factor

$h$

Fineness Ratio

Pod Height

\footnotetext{
*Aerospace Engineer, Aeronautics Systems Analysis Branch, 1 N. Dryden St. MS 442

†erospace Engineer, Aeronautics Systems Analysis Branch, 1 N. Dryden St. MS 442, AIAA Senior Member.

† Aerospace Engineer, Aeronautics Systems Analysis Branch, 1 N. Dryden St. MS 442
} 


$\begin{array}{ll}L & \text { Pod APU Section Length } \\ r & \text { Pod Side Radius } \\ R e & \text { Reynolds Number } \\ \text { Vol }_{\text {APU }} & \text { APU System Volume } \\ w & \text { Pod Width } \\ \mathrm{CD} & \text { Drag Coefficient } \\ \mathrm{CL} & \text { Lift Coefficient } \\ \text { LHV } & \text { Lower Heating Value }\end{array}$

\section{Introduction}

As the demand for higher-power electrical systems expands, unconventional or additional sources of aircraft electrical power generation are being investigated. "Hybrid-electric" aircraft architectures that leverage multiple or alternative power sources are also becoming more popular with rising concerns over efficiency. For example, NASA's Fostering Ultra Efficient, Low-Emitting Aviation Power (FUELEAP) project investigated a 120kW hybrid-electric power system architecture, with the majority of the net electrical power provided by solid oxide fuel cells (SOFCs) using reformed hydrocarbon fuel as the fuel source [1]. Fuel cells are particularly interesting as auxiliary or secondary electrical power generation devices, due to their relative efficiency and longevity, and could be used as a "power pod" for vehicles without enough on-board electrical generation capability.

Other forms of electrical power generation or storage, such as turbo-generators, batteries, small-engine generators (both standard and compression ignition), and air turbines have disadvantages that make them less attractive as auxiliary or secondary power for long-duration, small aircraft operations. Batteries, for example, are excellent at providing high amounts of power in short bursts and low amounts of power over a long period; however, they tend to be very heavy for the amount of energy available. The inherent inefficiencies of both small turbo-generators and small engines increase the amount of fuel required for the power pod, adding to vehicle emissions and fuel burn. Larger turbo-generators may be more efficient, but they require substantial sacrifices to payload or fuel capacity due to their weight while producing excess power well beyond what is necessary. Deployable air turbine generators require no dedicated fuel, are mechanically simple and therefore reliable, and can respond to power needs by varying blade pitch; however, the increased drag from driving the propeller contributes significantly to the aircraft's fuel burn.

In this paper, we will present methods for sizing a podded solid oxide fuel cell auxiliary power unit, an estimation of mission performance when the pod is installed on a baseline aircraft, and the potential value over time as compared to scaling the aircraft engines and electrical generators to meet power demands. For this study, a small aircraft is defined as a general aviation aircraft with six seats or fewer or Class-IV/V unmanned aerial vehicles greater than 1,320 lb. Benefits of using a podded SOFC auxiliary power unit (APU) on a small aircraft include:

1) the APU may be uninstalled or exchanged when high-power operations are unnecessary or the mission requires other cargo;

2) multiple small APUs could be used in modular configurations to meet different mission needs;

3) the SOFC provides enhanced mission capability for relatively low initial investment when compared to upscaling the engine and generators; and

4) the high efficiency of the SOFC power system results in minimal increases in mission fuel burn versus scaling the engine to provide the additional electrical power.

\section{Background}

This section serves to familiarize the reader with the trends, technologies, and tools related to the APU sizing and performance study. 


\section{A. Increased Power Demand}

Electrical instruments and equipment onboard aircraft and other vehicles have steadily increased in power over the years as the demands for higher quality information, communications, and capabilities have grown as shown in Fig. 1 [2]. To respond to these needs, devices that either store or generate additional power are integrated into the aircraft. For large vehicles, such as fighter or commercial transportation aircraft, the excess engine power or a large APU is usually sufficient to provide the additional electrical power needs. However, for smaller aircraft that have limited excess power or weight margins, simply upscaling the existing electrical system to achieve the desired power level may not be feasible or affordable. Of the various electrical power generation technologies that have been examined as potential solutions to increased electrical loads on small aircraft or long-endurance UAVs, fuel cells are attractive because of their substantial longevity, reliability, and efficiency.

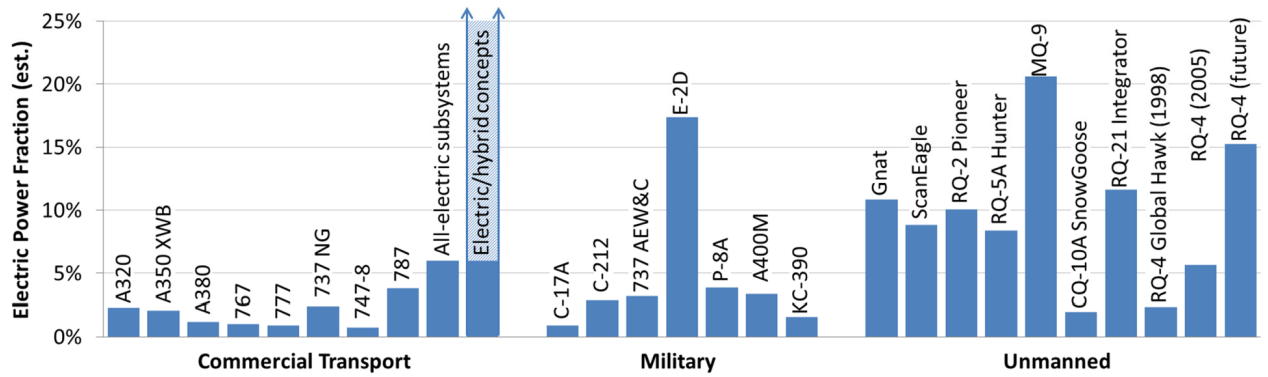

Fig. 1 Estimated electrical power fraction for various aircraft from Waters and Cadou, 2015 [2].

\section{B. Solid Oxide Fuel Cells}

Fundamentally, fuel cells use fuel and oxidant to operate in a similar way to batteries where an electricity producing chemical conversion takes place. However, unlike a battery that functions as an energy storage device, the fuel cell behaves more as an energy converter that should operate as long as fuel and oxidant are provided. Figure 2 illustrates the SOFC operation where fuel is supplied to the anode side and an oxidant, typically air, is supplied to the cathode side. The electrolyte transfers ions between the electrodes and allows electrochemical processes to take place [3]. Solid oxide fuel cells are highly attractive for long-endurance UAV application due to their ability to use reformed, heavy hydrocarbon fuels such as JP-8 [4].

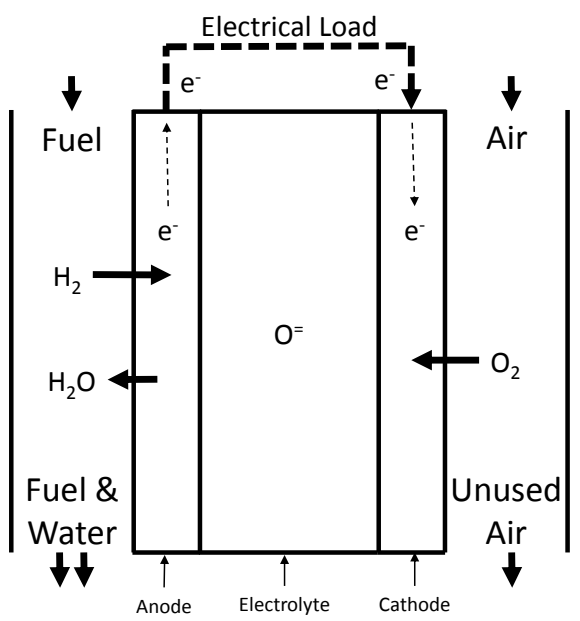

Fig. 2 Arrangement of a solid oxide fuel cell showing the path of fuel, oxidant, and electrons. 


\section{Tools and Methods}

FLOPS

The Flight Optimization System (FLOPS) [5] is a multidisciplinary system of modules that enable preliminary/conceptual design and analysis of aircraft. Nine primary modules make up the system, including Weights, Aerodynamics, Engine Cycle Analysis, Propulsion Data Scaling and Interpolation, Mission Performance, Takeoff and Landing, Noise Footprint, Cost Analysis, and Program Control. In this study, we used FLOPS as the primary mission performance analysis tool.

\section{OpenVSP}

Open Vehicle Sketch Pad [6] (OpenVSP) is a NASA-developed, open-source, parametric geometry design environment that enables the user to quickly generate 3-D models of objects using various components packaged with the software. Once a model has been created, it can be analyzed within OpenVSP using the built-in analysis tools or exported in a variety of formats for external analysis.

\section{VSPAERO}

VSPAERO [7] is a fast, linear, vortex-lattice based aerodynamics solver for use with OpenVSP models. The program can be executed either within OpenVSP via a graphical user interface (GUI) or manually via the command prompt. The program is also capable of integrating actuator disks into the model for aero-propulsive analysis.

\section{VSP Parasite Drag Module}

In 2017, a parasitic drag calculation module [8] was integrated into OpenVSP enabling the direct and rapid analysis of OpenVSP models within the modeling environment under varying flow conditions. The solver automatically derives all of the drag form factors for each component and applies them at the flow conditions specified. The user may choose from many different drag calculation methods and equations in combination depending on the flow regime being investigated. Futhermore, the user is able to add excrescence drag in several forms to adjust the drag model.

\section{Baseline Aircraft}

A representative aircraft useful in both civilian and military operations was needed to capture a large user base for growing power needs. As such, a General Atomics MQ-9 Predator B "Reaper" was chosen as it is representative of the state of the art long-endurance UAV. Data can also be compared to the NASA's "Ikhana" research aircraft which was an early derivative of the MQ-9. Such aircraft would benefit from expanded research instrument capabilities, high-power data systems, increased communications bandwidth, greater mission awareness, and other examples of feature enhancements.

\section{A. Geometry and Design}

A combination of listed dimensions [9] and photographs was used to establish an approximate model (Fig. 3) of the aircraft in OpenVSP. Table 1 lists the OpenVSP model's geometric parameters. This model was also used as a reference for performance modeling, weights, and mission analysis in a variety of tools.

Table 1 NASA Ikhana OpenVSP Model Dimensions

\begin{tabular}{l|c}
\hline \hline Parameter & Value \\
\hline Wingspan $(b)[\mathbf{f t}]$ & 66 \\
Length [ft] & 36.2 \\
Height [ft] & 12.5 \\
Wing Planform Area $(S)\left[\mathbf{f t}^{2}\right]$ & 270.6 \\
Aspect Ratio $(A R)$ & 16.1 \\
Wing Taper Ratio $(\lambda)$ & 0.464 \\
\hline \hline
\end{tabular}




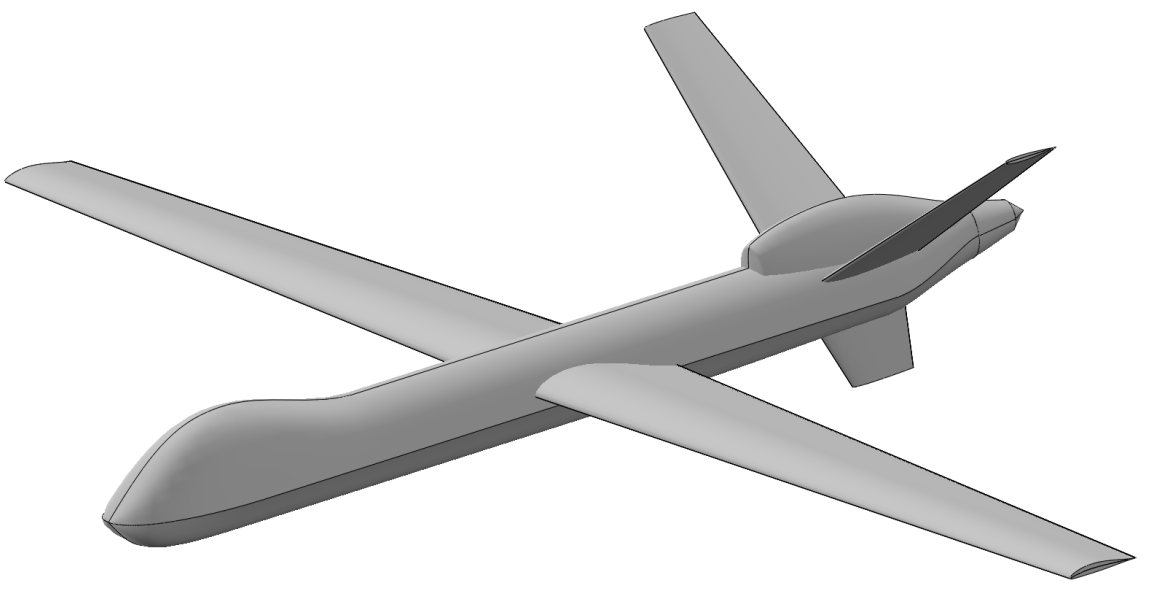

Fig. 3 OpenVSP model approximating the NASA Ikhana (based on GA-ASI MQ-9 data) [9].

\section{B. Mission and Performance}

We used the OpenVSP model and the VSPAERO vortex-lattice solver to estimate aerodynamic performance. Once the aircraft configuration and VSPAERO inputs were tailored to available data [9-11], we created a drag polar (Fig. 4) and aerodynamic lookup tables for FLOPS reference.

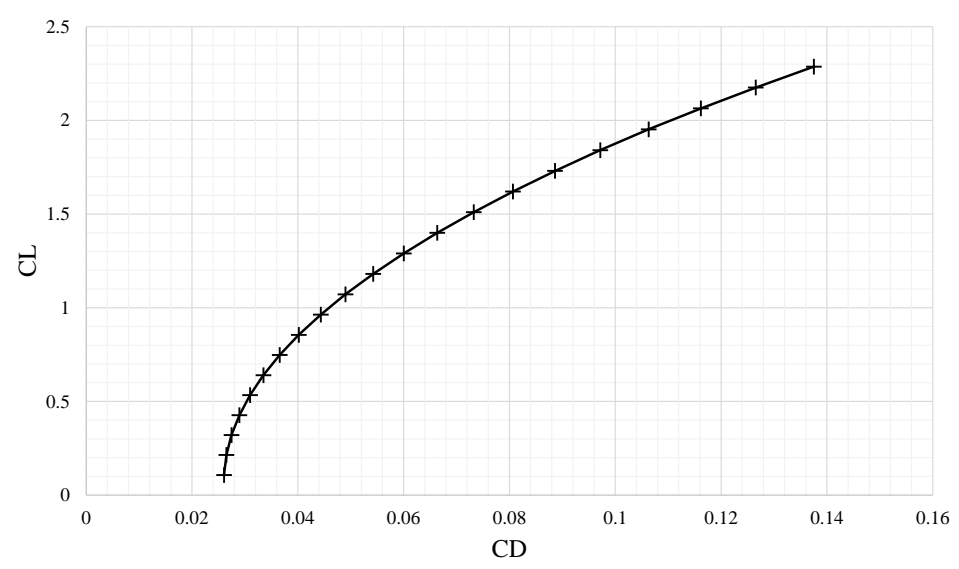

Fig. 4 Drag polar from VSPAERO used to estimate untrimmed aerodynamic performance.

Using the OpenVSP model parameters as well as performance metrics listed on the USAF MQ-9 Fact Sheet [9] and the 900 SHP Honeywell TPE331-10 Engine Spec Sheet [11], a FLOPS model was created to analyze the baseline model's mission performance and compare it to the Ikhana's performance $[9,10]$. The mission was defined as a Climb > Cruise $>$ Descent schedule where climb and descent profiles were based on minimum fuel-to-climb/descend, and cruise was based on the published endurance speed of 150 - 170 KTAS[11] and an altitude of 20,000 ft. We then modified the FLOPS and OpenVSP models to align the baseline model to the expected mission performance as summarized in Table 2. For example, the components contributing to the aircraft operating empty weight were either set according to published values or scaled from the original FLOPS estimate to achieve the listed empty weight of 4,900 lb. Figure 5 illustrates the resulting baseline weight breakdown for the selected mission. We also built a custom engine deck lookup table for the FLOPS analysis to more closely match the expected performance. Because the engine rated power was known, but the propeller performance and static thrust were not, the static thrust was scaled. Based on engine power, 
fuel flow data [11], and expected results, we achieved the published endurance mission duration of approximately 27 hours (26.35 hr.).

Table 2 Baseline FLOPS Mission Inputs and Performance Values

\begin{tabular}{l|c|l|c} 
Input Parameter & Value & Performance & Value \\
\hline Operating Empty Weight & $4,900 \mathrm{lb}$ & Design Range & $4,295.7 \mathrm{n} \mathrm{mi}$ \\
Payload & $1,700 \mathrm{lb}$ & Block Time & $26.35 \mathrm{hr}$ \\
Maximum Fuel & $3,900 \mathrm{lb}$ & Block Fuel & $3,705 \mathrm{lb}$ \\
Gross Takeoff Weight & $10,500 \mathrm{lb}$ & & \\
Thrust per Engine & $2,840 \mathrm{lbf}$ & &
\end{tabular}

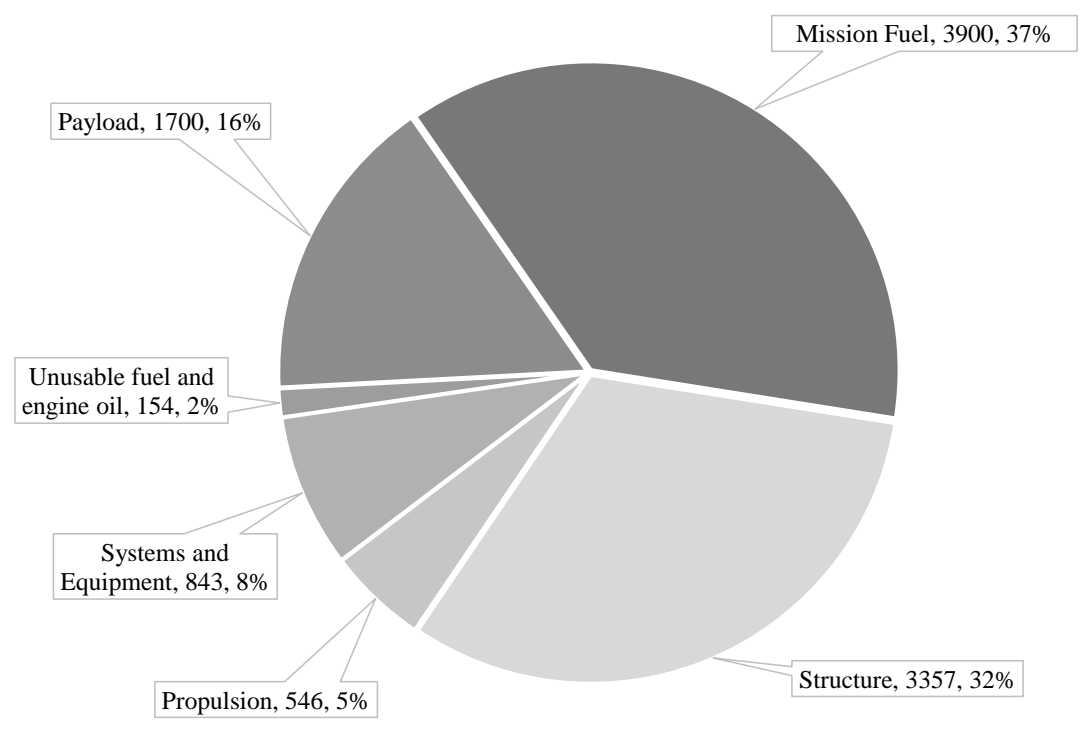

Fig. 5 Baseline weight breakdown for an endurance cruise mission.

\section{Initial Study}

To test the feasibility of applying the FUELEAP SOFC technology to a small aircraft, we constructed a simple sizing method for estimating the performance and weight of a SOFC APU pod by altering specific factors. Because this initial test contained relatively few degrees of freedom (Table 3), we implemented a full-factorial experiment and scripted the execution. The factor inputs were derived based on the $120 \mathrm{~kW}$ FUELEAP Design and Analysis Cycle "DAC- 1 " and "DAC-2" architectures [1]. The expectation was that the efficiencies would be similar but the power to weight ratio (specific power) would be less for lower-power systems. 
Table 3 Input Factors for Initial Sizing Tests

Factor
\begin{tabular}{|l|l|c|c|c|c|c|c|c|c|}
\hline SOFC Specific Power & W/kg & 150 & 200 & 250 & 300 & 350 & & 5 \\
\hline Power Needed & $\mathrm{kW}$ & 3.5 & 7 & 10.5 & 14 & 20 & 40 & 6 \\
\hline SOFC Efficiency & $\%$ & 0.53 & 0.62 & & & & & 2 \\
\hline Lower Heating Value & $\mathrm{MJ} / \mathrm{kg}$ & 42.6 & 48.6 & & & & & 2 \\
\hline
\end{tabular}

\section{A. SOFC APU Sizing}

The primary drivers of the SOFC weight were the power-to-weight ratio, or mass-specific power [W/kg], and desired power output $[\mathrm{kW}]$. By choosing a value for steady-state power output and also considering an extra $10 \%$ power for battery charging and peak loads, the expected weight of the fuel cell could be approximated by $W_{S O F C}=P_{\text {out }} / P_{S p_{S O F C}}$, where $W_{S O F C}$ is the fuel cell weight, $P_{\text {out }}$ is the total system power output, and $P_{S p_{S O F C}}$ is the mass-specific power. Based on the FUELEAP DAC designs [1], we used a simple linear interpolation of the total averaged system mass density, less batteries, to determine the expected SOFC volume. To account for packing inefficiencies at small scales, a $10 \%$ packing factor was applied to the SOFC system volume in addition to the packing already included in the FUELEAP design.

\section{B. Battery Sizing}

Batteries are assumed to supply the peak load power demand resulting from short-duration, high-power operations of electrical equipment. In this case, the peak loads and duration of operation were used to determine the charge at $70 \%$ depth of discharge for a given battery design. Using a proprietary set of existing battery data available to NASA, the option resulting in the best mass-specific energy for each required was chosen. Because the peak loads were assumed to be a certain fixed percentage above the steady-state power requirements, the best battery option for each case had a specific energy of approximately $150 \mathrm{Wh} / \mathrm{kg}$. Combining the total required charge and specific energy resulted in a total battery weight for the given system parameters. The battery pack was assumed to have an additional $50 \%$ over the total cell mass. An approximation for the mass density of the battery pack design was chosen from the manufacturer's information and so determined the total battery volume.

\section{Fuel Cell Fuel Sizing}

We chose to use reformed JP- 8 fuel for this study due to the availability and low relative cost. The SOFC fuel conversion efficiency was used to determine what percentage of the fuel lower heating value (LHV) is available for energy. Using the expected operating duration and the power output, the total mission energy was established and then used to find the required SOFC fuel weight. To account for fuel reserve, a 5\% increase to fuel cell fuel volume, based on JP-8's density $\left(48.38 \mathrm{lb} / \mathrm{ft}^{3}\right)$ [12] was added. An additional $5 \%$ increase in total fuel cell fuel volume provided the required tank volume, including void space for filling. The tank weight was estimated as $5 \%$ of the fuel weight for the initial sizing study. To account for APU pod structural weight, an additional 10\% was added to the sum of the SOFC, battery, and fuel/tank weights.

\section{APU Pod Sizing}

The SOFC APU pod was sized to contain all of the necessary components, including the fuel cells, batteries, structure, and fuel. The calculated volumes for each component were summed and then an additional 10\% packing factor was applied to determine the total required pod volume. Dimensions for the pod were established from geometric ratios between pod width and height and the length needed to accommodate the system volume. Figure 6 illustrates the notional dimensions of a pod. The enlarged front view shows the relationships between dimensions for sizing the APU pod cross-section. The height, $h$, is set as $2 / 3$ width, $w$, and the sides are semi-circles with radius, $r$. 


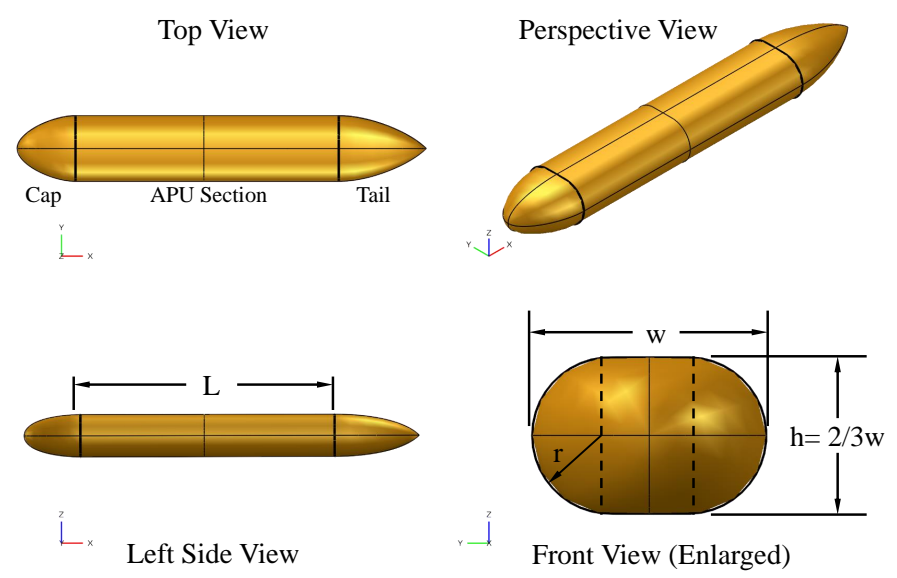

Fig. 6 SOFC APU pod diagram with relevant dimensions.

To simplify the calculations, the fore and aft sections, or pod caps, were assumed to have a fixed length relative to the rest of the pod. For the purposes of this analysis, the cap and tail sections are considered empty spaces in the pod and add surface area. Because the sizing equations for the SOFC system and fuel may be optimistic, this additional conservatism was deemed acceptable for initial tests. A fineness ratio $(F R=L / w)$ of 4.0 was used to size the APU section of the pod, which determined the pod width. As every other pod dimension is width-dependent, the entire pod geometry can be derived from an input system volume and fineness ratio as shown in Eqs. (1) and (2) where $V_{o l} l_{A P U}$ is the APU pod volume and $A_{s e c}$ is the pod cross-sectional area. This significantly reduced the degrees of freedom and simplified the sizing process. Furthermore, the simple relationships between the pod parameters were easily implemented in the OpenVSP model where the pod geometry could be automatically generated using the desired pod width as a single controlling input.

$$
\begin{gathered}
V o l_{A P U}=L * A_{s e c}=F R * \frac{w}{9}(\pi+2) w^{2} \\
w=\left[\frac{9 * V o l_{A P U}}{F R(\pi+2)}\right]^{1 / 3}
\end{gathered}
$$

Once the pod geometry was determined, a fixed pod material thickness of $0.050 \mathrm{in}$. was used to calculate the pod shell weight, assuming an aluminum shell (density of $169 \mathrm{lb} / \mathrm{ft}^{3}$ ) for cooling and rigidity. Having sized the pod geometry and weight, these parameters were used to analyze the baseline aircraft performance with the SOFC APU pod mounted to a fuselage hard point by calculating the change in parasitic and induced drag for a given flight condition. Figure 7 illustrates an example podded configuration.

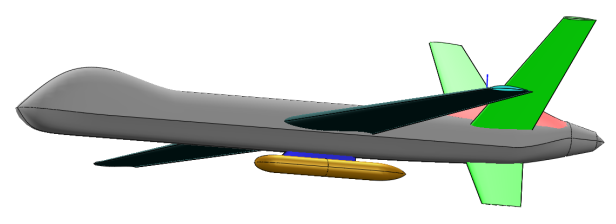

Fig. 7 An example of the SOFC APU pod mounted to the aircraft.

\section{E. Initial Results}

The initial test examined the additional fuel burn resulting from adding the notionally sized SOFC APU pod to the MQ-9 aircraft model. A simple drag comparison between the baseline aircraft and the podded configuration determined the fuel burn and reduced the analysis complexity. The APU weight was assumed to be in addition to the 10,500 lb 
takeoff weight. The induced drag was derived from the lift required for level flight using VSPAERO and the vehicle parasitic drag was determined according to the methods listed in Section V.C.

Figure 8 shows a contour plot of the resulting fuel burn increase in pounds per hour, pph, as a function of additional APU power output and APU specific power. The results of the initial study seemed surprisingly optimistic considering the size and power of the SOFC pod attached. Therefore, we implemented more detailed sizing methods and opted to use FLOPS-estimated mission performance as a more rigorous analysis.

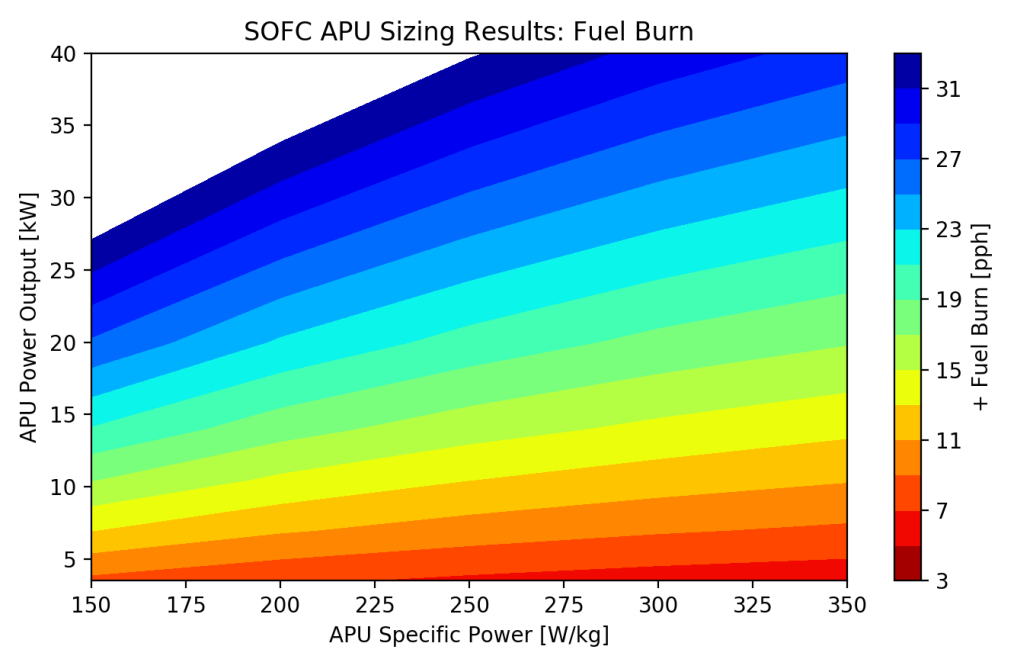

Fig. 8 Estimated fuel burn increase from SOFC APU pod attached to fuselage.

\section{Mission Performance Experiment}

To examine the feasibility or affordability of using a SOFC system on board the MQ-9, an experiment was derived to explore the design space and to feed trade studies between performance and cost. This experiment built on the lessons learned from the initial sizing study and incorporated additional information into the updated sizing methods. Rather than examining the additional fuel burn resulting from the updated pod designs against the baseline mission only, we decided to also analyze the additional fuel burn from scaling the existing 900 SHP TPE331-10 engine. The engine scaling option was expected to strongly outperform the SOFC APU due to the relatively small increase in required shaft power to produce the additional output electrical power. However, the cost of changing the engine in the MQ-9 was expected to be greatly larger than the cost of adding a SOFC pod, therefore a notional cost comparison was also performed to establish the value of investing in SOFC technology for an aircraft of this scale.

\section{A. Determining Relevant Factors}

Using the initial sizing method, we performed an analysis of variance, with a Taguchi L8 orthogonal array, on the variables to establish the most dominant factors affecting system weight and drag. At a constant power output, mission duration, and battery size for a given design, the driving factors were SOFC specific power and LHV conversion efficiency. Therefore, these factors were added to a full-factorial design of experiments which also included power output and SOFC operating time as well as engine scaling options (Table 4). 
Table 4 Input Factors for Full-Factorial Experiment

\begin{tabular}{|c|c|c|c|c|c|c|c|c|}
\hline APU Pod Sizing Factors & Units & 1 & 2 & 3 & 4 & 5 & 6 & Levels \\
\hline SOFC Specific Power & $\mathrm{W} / \mathrm{kg}$ & 150 & 200 & 250 & 300 & 350 & & 5 \\
\hline Power Output & $\mathrm{kW}$ & 5 & 10 & 15 & 30 & 60 & & 5 \\
\hline SOFC Efficiency & $\%$ & $50 \%$ & $60 \%$ & & & & & 2 \\
\hline SOFC Fuel (Time Operating) & hrs & 10 & 15 & 20 & 25 & & & 4 \\
\hline \multicolumn{9}{|l|}{ Engine Scaling Factors } \\
\hline Power Output & $\mathrm{kW}$ & 5 & 10 & 15 & 30 & 60 & & 5 \\
\hline
\end{tabular}

TOTAL NUMBER OF TESTS 205

\section{B. Updated SOFC APU Pod Sizing}

We implemented a variety of updates to the sizing methods to remove some of the inherent optimism in the model, incorporate system sizing and performance estimates from FUELEAP SOFC system designs, and to more realistically model the various system components.

\section{Mission Duration}

To better represent the use case of an APU, the operational duration was varied in the experiment. Assuming that the additional power output would only be needed while the aircraft was on station, or perhaps that the maximum power output would not be needed for the entire mission, allowed for an additional degree of freedom when sizing the system. This essentially allowed the amount of stored APU fuel in the system to be varied while keeping all other parameters relatively unchanged. The most significant effect of this modification was on the total weight of the SOFC APU system which, in turn, affected the induced drag. However, the size of the fuel tank remained capable of a $25 \mathrm{hr}$. mission duration to appropriately model only partially filling the tank.

\section{Fuel Tank Sizing}

The fuel tank sizing was changed from a fixed percentage of volume and weight to a more representative model that assumed a spherical, urethane rubber bladder within the APU pod, maintaining the 5\% margins for fuel reserve and tank void space. To determine the tank weight, the spherical surface area is calculated from the tank diameter and then a $1 / 100$ ratio of wall thickness to surface area is used to determine the volume of the tank material. A urethane rubber density value of $78 \mathrm{lb} / \mathrm{ft}^{3}$ was used to calculate the fuel tank weight [13].

\section{SOFC System Sizing}

The initial study used incremental packing efficiencies to account for additional volume in each component of the SOFC APU system. However, because the scaled SOFC volume was derived from the FUELEAP DAC models [1], SOFC packing efficiency was already accounted for. Rather than attempt to account for these values separately, we decided to treat the system as an integrated unit and applied an overall packing efficiency of $90 \%$ to the total volume.

A FUELEAP subcontractor provided fuel cell system sizing for outputs powers from 5 to $60 \mathrm{~kW}$ which we then used to update the SOFC system sizing methods $[4,14]$. With this data we were able to form a much more representative model of a possible SOFC APU pod and set accurate data points for comparison with the general sizing method. The calculations used the full 25 hour fuel capacity for each configuration to be conservative. However, the estimated mission duration tends to be significantly less than 25 hours. This implies that the fuel sizing for the manual method should be updated to better reflect the mission length and perhaps an iterative sizing process could be performed as part of future work. 


\section{Parasite Drag Calculation}

We estimated parasitic drag using OpenVSP's Parasite Drag solver [8] and the MQ-9 model. Fully turbulent, incompressible flow (Eq. (3)), based on low Reynolds number, was assumed to provide an upper bound on the expected vehicle and pod drag. Table 5 lists the form factor equations used to calculate the friction coefficient in the parasite drag model. Additional interference factors were applied to the model to simulate drag resulting from bodies in close proximity and a $20 \%$ excrescence factor was applied to account for surface imperfections and any unaccounted-for drag sources [15]. The drag coefficient, $C_{D}$, was calculated according to Eqs. (7) and (8).

Table 5 Form Factor Equations for MQ-9 Model Components

\begin{tabular}{l|l|c} 
Component & Form Factor Equation & Eqn. No. \\
\hline Fuselage & Hoerner Streamlined Body [16] & Eq. (4) \\
Engine Cowling & Hoerner Streamlined Body & Eq. (4) \\
Wing & Hoerner Wings [16] & Eq. (5) \\
Tails & Hoerner Wings & Eq. (5) \\
Pylon & Hoerner Wings & Eq. (5) \\
Pod & Jenkinson Aft Fuselage-Mounted Nacelle [17] & Eq. (6)
\end{tabular}

$$
\begin{gathered}
C_{f}=\frac{0.472}{\log (R e)^{2.5}} \\
F F=1+1.5\left(\frac{l}{d}\right)^{-1.5}+7\left(\frac{l}{d}\right)^{-3} \\
F F=1+2\left(\frac{t}{c}\right)+60\left(\frac{t}{c}\right)^{4} \\
F F=1.5 \\
f=S_{w e t} * Q * C_{f} * F F \\
C_{D}=\frac{f}{S}
\end{gathered}
$$

\section{FLOPS Inputs}

As previously discussed, the baseline FLOPS parameters were selected based on a 26.35 hour endurance cruise mission profile and calibrated using a Honeywell TPE331-10 engine deck and aerodynamic performance tables. Because FLOPS does not inherently allow the user to choose alternate power sources for various power loads, we determined that all of the additional power output would be supplied by the SOFC APU. For this experiment, the APU fuel remains constant throughout the mission i.e., the APU fuel weight does not decrease over time, and therefore the aircraft performance is penalized by carrying this weight. A future study would allocate the SOFC APU fuel in addition to the maximum fuel capacity, or more specifically return the APU fuel weight to aircraft fuel weight, and insert a "fuel leak rate" (FLEAK) that corresponds to the expected SOFC fuel conversion rate. This would allow the SOFC APU fuel to deplete while operating and more accurately model the mission performance. The current analysis is therefore an upper bound on actual mission fuel burn.

The takeoff weight is fixed at 10,500 $\mathrm{lb}$ or the maximum allowable takeoff weight listed for the MQ-9, equaling the total of 4,900 lb empty weight, 3,900 lb of fuel, and $1,700 \mathrm{lb}$ of payload. We assumed that payload capacity was fixed at $1,700 \mathrm{lb}$ for each mission. This implies that any weight increases from modifying the aircraft systems or the 
addition of the SOFC APU would require an equal decrease in fuel weight and therefore reduce the maximum possible mission duration. Notably, the sizing methods are not limited to this assumption and should the user wish to iteratively size a SOFC APU to meet a specific output power and payload configuration, it is relatively simple to determine a configuration that will also result in greater mission duration capability.

Of the available FLOPS input parameters, we identified three primary contributors to mission performance that had a strong connection to the SOFC APU sizing. These parameters were wing cargo weight (CARGOW), electrical system weight (WELEC), and parasitic drag factor (FCDO). Two additional parameters having stronger ties to scaling the engine are thrust (THRUST) and extracted customer power (HPEXT).

FLOPS only uses the wing cargo weight value for wing weight calculations e.g., structures, and the value has no effect on the current analysis because it was fixed to the baseline results. Therefore, we simply added the additional cargo weight of the APU pod to the wing cargo.

The electrical system weight is the combined total of all electrical power generation, storage, and distribution components on the aircraft such as motor generators, batteries, wiring, electrical buses, etc. Because the SOFC APU carries its own electrical systems and batteries to supply peak loads, the APU electrical weight is not considered part of this value. However, the aircraft electrical system must be able to distribute the additional power to systems and therefore some percentage of the electrical weight must be scalable. We set $20 \%$ of the electrical system weight as scalable electrical distribution components and a further $10 \%$ of the electrical system weight as scalable generators. The generators are only scaled for the increased engine output option of the study as it is only in this case that the additional power must be converted from the engine. In all other cases, the additional power output is provided by the SOFC APU and the generators remain unscaled to provide a fixed amount of critical aircraft electrical power. The electrical distribution system is simply scaled by the ratio of total electrical power to baseline electrical power. The extracted power parameter, HPEXT, is derived from the required electrical power generation and an overall electrical conversion efficiency, in this case assumed to be $93 \%$, and also remains fixed for all but the engine scaling tests.

The parasitic drag factor scales the lift-independent parasitic drag values for the mission segment flight condition and simulates the addition of external stores or drag sources. Each APU pod configuration must be analyzed with the OpenVSP Parasite Drag tool to determine the scaling factor applied for that test.

In all, this model is very conservative, assuming full-power for the operational duration and carrying margin and excess weight in addition to pessimistic aerodynamic performance. We opted to begin with an overly conservative model so that if the value of a SOFC APU was deemed insufficient for investment, the performance would be enhanced by improving the model accuracy or fidelity rather than attempting to enhance performance through costly design changes.

\section{E. Engine Scaling}

We modeled the upscaled engine option using thrust, power extraction, and electrical system weight. For a given engine deck, FLOPS has the ability to scale the engine performance and weight based on a desired static thrust. Therefore, the input static thrust was calculated from the estimated ratio of total shaft power to the baseline 900 SHP engine. The electrical system weight was scaled using the percentages described in section V.D, where, in these cases, the electrical distribution system and generator weights are both dependent on total electrical power. The additional power extracted from the engines was modeled using the $93 \%$ electrical conversion efficiency value and the total required electrical power. Because the additional power output is a relatively small fraction of the available 900 SHP baseline, we assumed that the engine's physical dimensions would not be significantly altered and therefore the parasitic drag would be unchanged.

\section{F. Cost Estimation}

Determining the cost-effectiveness of a SOFC system is difficult as the size, weight, and mission performance are highly sensitive to increased power output. To provide insight into the potential of such a system, we created a tool that uses installation and operating costs as inputs to compare value over time. In this case, the operating costs are simply based on additional fuel burn for producing extra output power which is calculated in the sizing methods. The fuel costs are based on the Defense Logistics Agency's FY2019 Standard Price for JP-8 (\$2.98 per gallon) as of October 1, 2018[18]. The annual operating cost for a single aircraft is found by assuming very heavy use at 20 hours per day, 5 days per week, all year long or a total of 5,200 operational hours per year. This is an excessively high operational use and, continuing the theme of the analysis, is considered an upper bound on the results.

The cost estimation tool allows users to select an additional power output in $\mathrm{kW}$ and an initial installation cost for both a SOFC system and a new engine. The operating costs are automatically selected from the data based on the 
desired power. A primary output of the tool is the breakeven time when using a SOFC system surpasses the cost of rescaling the engine. Given the inputs above, the tool calculates the amount of time in years that a SOFC system has less total cost than the engine option. The tool also has the ability to iteratively calculate the maximum acceptable price of a SOFC system given an initial engine rescaling cost, expected time in service, and desired output power.

\section{G. Execution}

We created a Python script to automate the analyses and collect data. Beginning in Microsoft Excel, the full-factorial design of experiments was automatically created with Visual Basic (VBA) scripts and the input factors listed in Table 4. Another VBA script automatically read the combination of inputs for a given test ID, inserted those values into the SOFC APU sizing equations, and then recorded the results. The Python script then modified and executed a template OpenVSP script which altered the podded MQ-9 model and called the Parasite Drag tool with the relevant values and updated geometry. The resulting parasitic drag coefficient was recorded in the results and used to finish calculating the required FLOPS inputs for mission performance analysis.

The Python script then reads the FLOPS inputs associated with each test ID, modified a template input namelist file, and executed FLOPS. Upon completing the FLOPS analysis, the script read the new output file and stored the relevant data in the results. Finally, the various mission performance parameters such as design range, flight time, and block fuel were used to determine the mission fuel burn increase, total fuel burn increase including APU fuel, and additional operating cost over the baseline. The entirety of this process is illustrated in Fig. 9 where the data flow from one module or program to another is shown along with the iterative loops where calibration or sizing convergence occur.

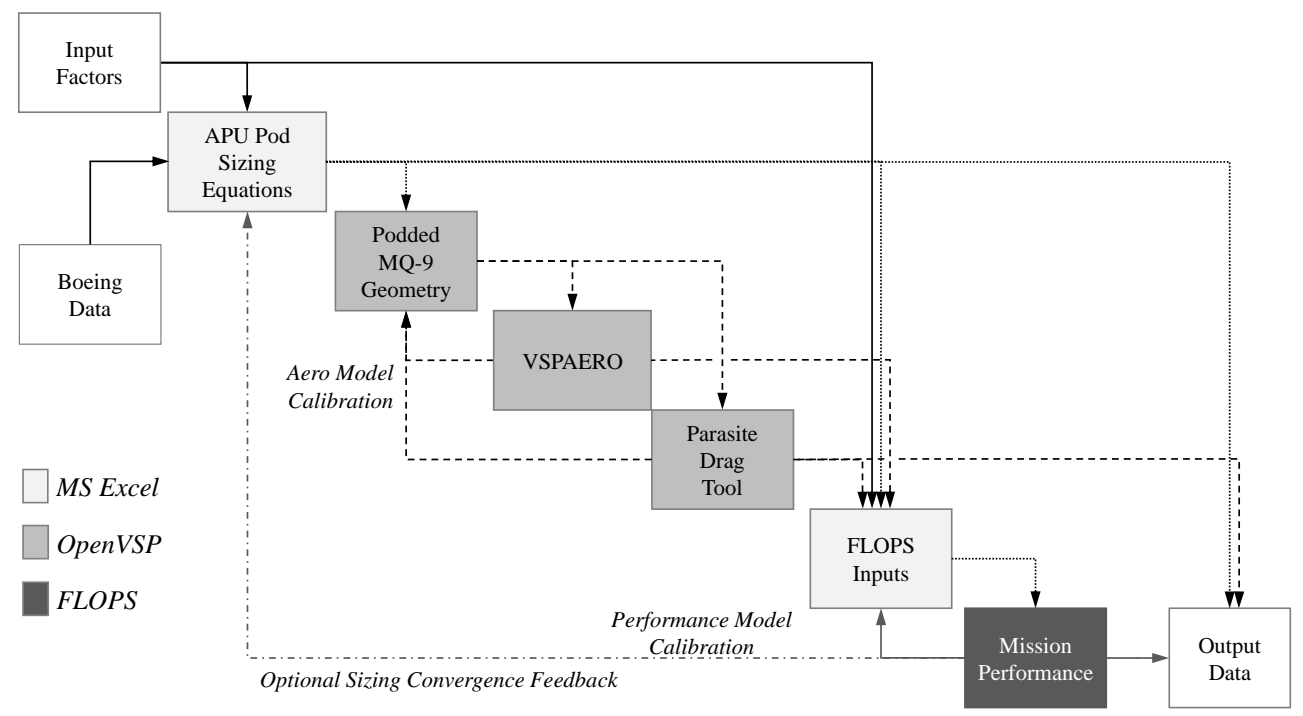

Fig. 9 N-squared diagram representing the sizing and analysis method.

\section{Results}

The FUELEAP subcontractor-provided SOFC performance estimates included a lower power but less efficient option \#1, a more efficient option \#2 that could not be sized less than $10 \mathrm{~kW}$, and a high power and efficiency option \#3 rated at $60 \mathrm{~kW}$ [14]. Assuming a desirable output power range of 10-30 kW, we chose the second option for comparison against scaling the engine and SOFC sizing estimates. Figure 10 lists the SOFC APU pod volume and weight, fuel weight, and increased mission fuel burn for the 10, 30, and $60 \mathrm{~kW}$ versions of the Option 2 design. Also shown are the sizes of each APU relative to the MQ-9 aircraft. Note that the fuel volume and weight are included in the pod volume and system weight.

The overall performance is shown in Fig. 11 where the sized SOFC APU variations, engine scaling, and power system options are compared. As predicted, scaling the engine is a far more effective means of producing extra power throughout the output range examined. Even the mininum fuel burn cases at each power level, resulting from highly 
optimistic SOFC performance values, do not approach the engine performance. However, the linear trend of power from scaling the engine would seem to eventually lose out to fuel cells at a additional output around 100 to $200 \mathrm{~kW}$. This also happens to be near the FUELEAP SOFC X-57-F power of $120 \mathrm{~kW}$ [1].

It makes sense that the subcontractor designs would fall within the sizing results as the point performance parameters are bracketed by the SOFC sizing inputs. Recall that the point pod sizing and mission performance are based on a full 25 hour fuel weight. With that in mind, the model's inherent conservatism is apparent in the results where many of the longer operational duration tests lie well above the trendline. Interestingly, it appears that the SOFC efficiency and pod sizing are not quite trending with power output as predicted by the subcontractor models. Some low-power inefficiencies and high-power gains could be estimated from this data and integrated into the SOFC sizing to more accurately represent these effects.

The most important result of this study is the apparent value of a SOFC APU system and how it compares to that of scaling the aircraft engines. Figure 12 illustrates a scenario where the per-aircraft installation cost of a podded $10 \mathrm{~kW}$ SOFC system is $\$ 300,000$ and installing a new engine is very optimistically priced at $\$ 1,000,000$. Based on an extreme use case of 5,200 hours per year, it would still take approximately 24 years before the running cost of the SOFC system surpassed that of the new engines, even though the fuel cell option has much higher additional operating costs. This is longer than the 22 year operational lifetime of the MQ-1B Predator which entered in 1996 and retired in 2018 [19, 20]. In this scenario, the SOFC APU seems to have a significant advantage in value over engine scaling and would result in considerable savings throughout the expected life of the aircraft. Additionally, with an estimated mean time between failures on the order of tens of thousands of hours, the fuel cell system is highly reliable. If we assume a slightly more realistic use case of 20 hours per mission, 3 days per week, 26 weeks out of the year (1560 hours/year) the resulting estimated breakeven time is 80 years. This information suggests that the bulk of cost savings is due to the difference in installation costs between the systems. Moreover, because the operational costs for each system are relatively low in this case, the initial savings could be considered effectively permanent for the life of the aircraft.

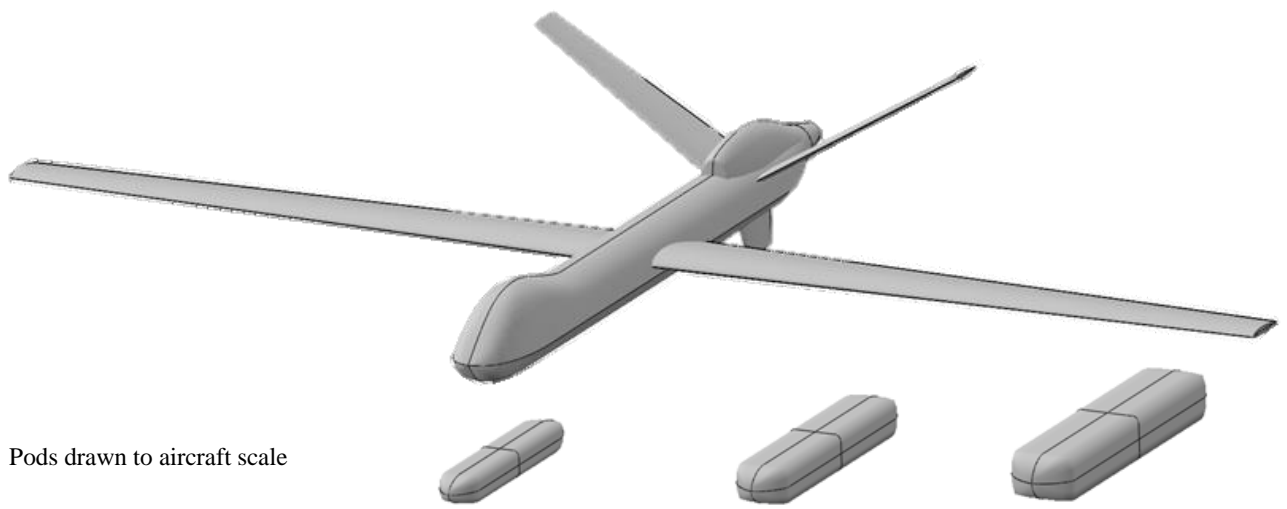

\begin{tabular}{|c|c|c|c|}
\hline Power Output & 10 kW Pod & 30 kW Pod & 60 kW Pod \\
\hline Pod Volume (System Weight) & $17.01 \mathrm{ft}^{3}(343.7 \mathrm{lbs})$ & $40.09 \mathrm{ft}^{3}(826.1 \mathrm{lbs})$ & $72.91 \mathrm{ft}^{3}(1517.2 \mathrm{lbs})$ \\
\hline Fuel Volume (Fuel Weight) & $2.54 \mathrm{ft}^{3}(122.8 \mathrm{lbs})$ & $6.61 \mathrm{ft}^{3}(319.6 \mathrm{lbs})$ & $12.49 \mathrm{ft}^{3}(604.4 \mathrm{lbs})$ \\
\hline$\Delta$ Aircraft Fuel Burn & $11.33 \mathrm{pph}$ & $18.52 \mathrm{pph}$ & $26.47 \mathrm{pph}$ \\
\hline
\end{tabular}

Fig. 10 Sizing results of podded SOFC APU system for 10, 30, and $60 \mathrm{~kW}$ power output. 


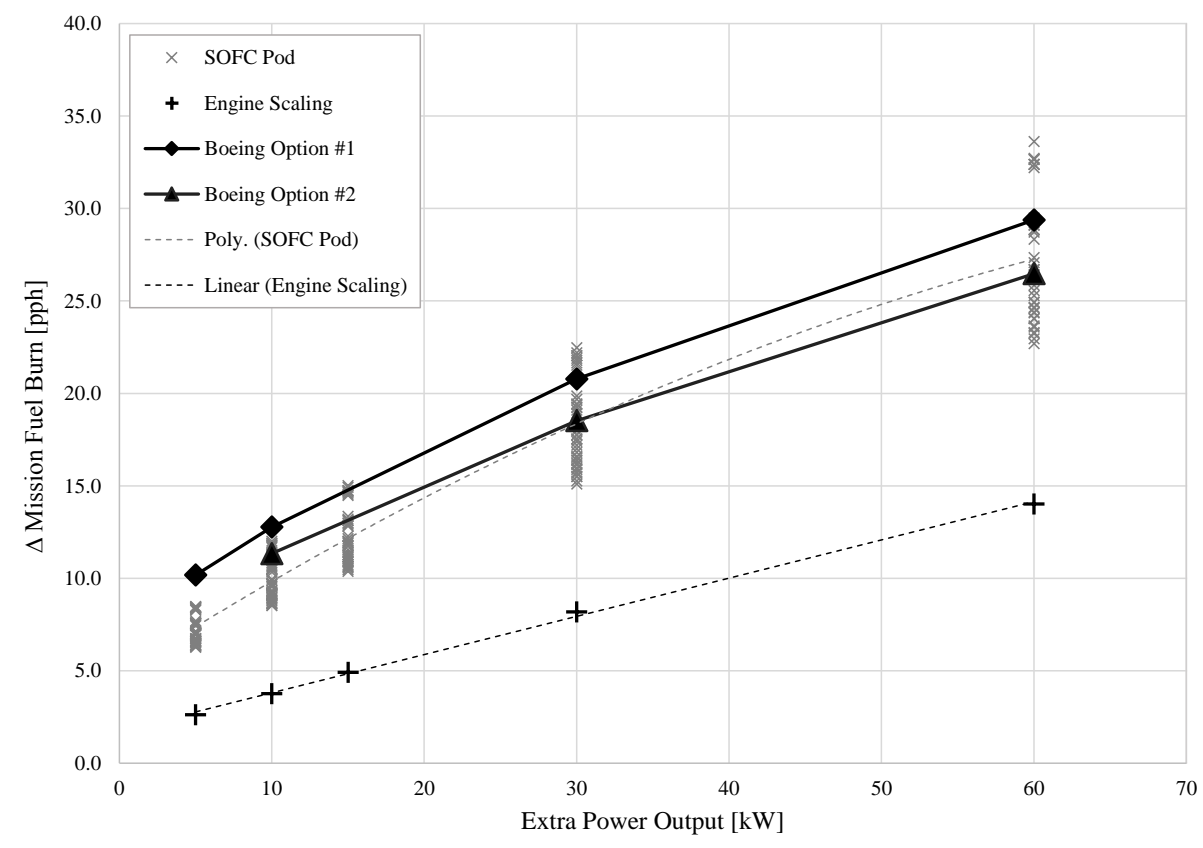

Fig. 11 Increased mission fuel burn for alternative means of increased electrical power output.

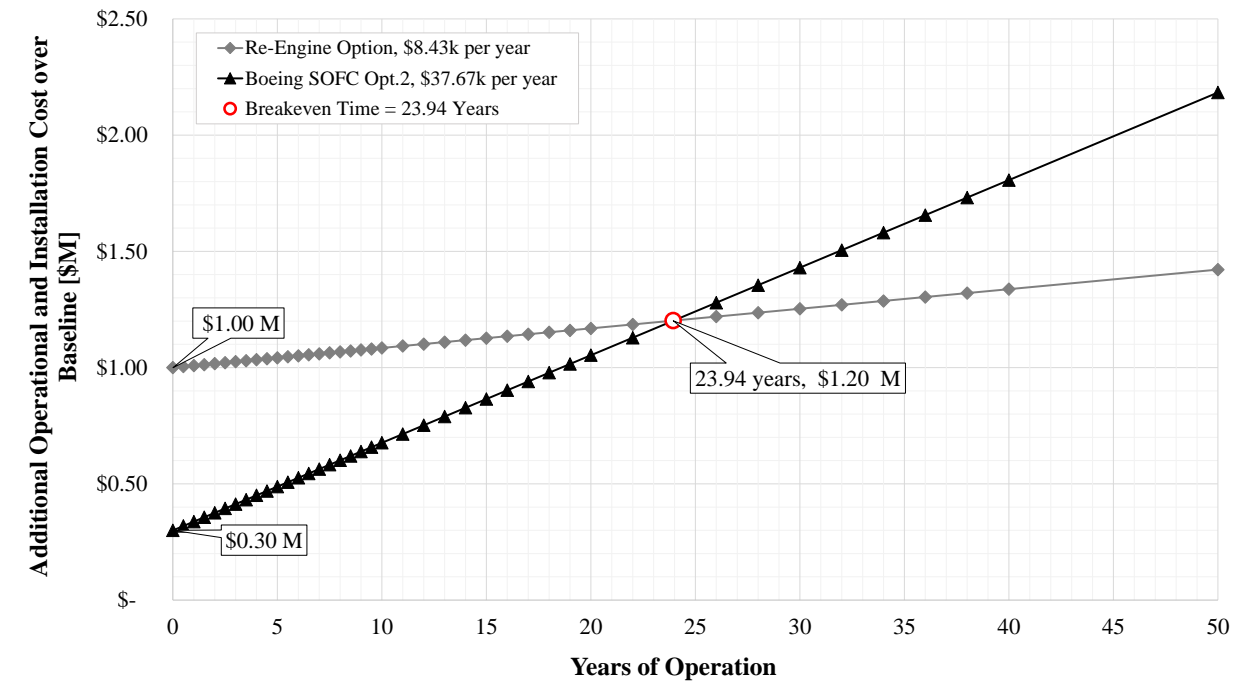

Fig. 12 Additional cost comparison over baseline of a podded $10 \mathrm{~kW}$ SOFC system vs. engine scaling over time for a single aircraft assuming $5,200 \mathrm{hr} / \mathrm{yr}$ operation at $\$ 2.98 / \mathrm{gal}$.

\section{Concluding Remarks}

The results of this study indicate that using a SOFC system as a podded APU is a highly cost-effective option for producing increased electrical power and enhancing mission capability on a small aircraft. The low estimated initial investment drastically reduces the total additional cost over time, even with comparatively higher operating costs versus scaling the engine. Furthermore, the SOFC system dramatically reduces the amount of harmful emissions when 
compared to combustion. In contrast to upscaling the engine, the podded APU may be uninstalled or exchanged for other stores when high-power operations are reduced or unnecessary. Also, multiple small APUs could be used in modular configurations to meet a variety of mission needs and enhance the aircraft's versatility and responsiveness to changing environments. It is important to note that we did not disregard the option of drawing additional power from the existing engine but rather considered a reduction in available power for thrust or loss of maneuvering capability a significant risk contribution to the aircraft and unacceptable. Another consideration is that any power generated in excess of payload requirements could be used to power aircraft systems and therefore reduce the engine power extraction from the generators. This could provide some additional thrusting capability or extend the range or duration of the mission.

We recognized several areas where the sizing methods or performance models could be improved including:

- updating the SOFC performance model to more accurately represent FUELEAP subcontractor estimates;

- eliminating excessive void space in the APU pod cap and tail;

- improving the APU pod shape;

- choosing a less conservative aerodynamic model that includes some laminar flow over aircraft components;

- inserting a fuel burn rate that accounts for SOFC fuel use over time;

- sizing the system for 20 hours of operation rather than 25 hours;

- removing overly conservative results where the SOFC fuel available exceeds the mission duration; and

- more accurately modeling mission power use by examining peak loads and non-constant full-power operation.

A future study could examine the effects on missions where duration is emphasized over payload, assuming some minimum payload for electronic devices or arms. Also, a trade space exploration could be performed that iteratively converges SOFC APU sizing for a desired payload and range or duration. This study could provide insight into the potential benefits of a highly modular, multiple APU configuration where the electronics payload and excess power generation are matched to maximize capability and range.

\section{Acknowledgments}

This work was funded by NASA's Aeronautics Research Mission Directorate (ARMD) under the Transformational Aeronautics Concepts Program. In particular, this research was part of the Fostering Ultra-Efficient, Low-Emitting Aviation Power (FUELEAP) subproject of the Convergent Aeronautics Solutions Project. The authors thank NASA for their support of FUELEAP.

\section{References}

[1] Borer, N. K., Geuther, S. C., Litherland, B. L., and Kohlman, L. W., "Design and Performance of a Hybrid-Electric Fuel Cell Flight Demonstration Concept," doi:10.2514/6.2018-3357, URL https://arc . aiaa.org/doi/abs/10.2514/6.2018-3357.

[2] Waters, D. F., and Cadou, C. P., "Optimization of Gas Turbine - Solid Oxide Fuel Cell Systems for Aircraft Power Generation,” $53 r d$ AIAA Aerospace Sciences Meeting, doi:10.2514/6.2015-0624, URL https://arc . aiaa.org/doi/abs/10.2514/6.20150624.

[3] National Energy Technology Laboratory, “Solid Oxide Fuel Cells Technology Program Plan,” Tech. rep., United States Department of Energy, 2013. URL https://www.netl.doe.gov/File\%20Library/Research/Coal/energy\%20systems/ fuel\%20cells/Program-Plan-Solid-Oxide-Fuel-Cells-2013.pdf, Accessed: 5/7/2019.

[4] Stoia, T., Atreya, S., and O’Neil, P., “A Highly Efficient Solid Oxide Fuel Cell Power System for an All-Electric Commuter Airplane Flight Demonstrator," 54th AIAA Aerospace Sciences Meeting, doi:10.2514/6.2016-1024, URL https://arc . aiaa . org/doi/abs/10.2514/6.2016-1024.

[5] NASA, "Flight Optimization System, Release 8.26 User's Guide,”, 2015.

[6] “OpenVSP,”, 2018. URL www . openvsp.org, Accessed: 5/7/2019.

[7] Litherland, B., NASA Langley Research Center, "Using VSPAERO,”, 2015. URL http://openvsp.org/wiki/doku .php? id=vspaerotutorial, Accessed: 5/7/2019.

[8] Gravett, J., Empirical Systems Aerospace, "Parasite Drag Tool,", 2018. URL http://openvsp.org/wiki/doku.php?id= parasitedrag, Accessed: 5/7/2019.

[9] USAF, “MQ-9 Reaper,", 2015. URL http://www .af.mil/About-Us/Fact-Sheets/Display/Article/104470/mq-9reaper/, Accessed 03/10/2018. 
[10] General Atomics Aeronautical Systems Inc., "MQ-9 Reaper/Predator B,", 2015. URL http: //www . ga-asi . com/Websites/ gaasi/images/products/aircraft_systems/pdf/MQ9\%20Reaper_Predator_B_032515.pdf, R 041514, Accessed: $5 / 7 / 2019$.

[11] Honeywell Aerospace, “TPE331-10 Turboprop Engine,”, 2009. URL https://aerocontent.honeywell.com/aero/ common/documents/myaerospacecatalog-documents/BA_brochures-documents/TPE331-10_PredatorB_0292000.pdf, N61-0292-000-001, Accessed: 5/7/2019.

[12] Schmitigal, J., and Tebbe, J., "JP-8 and Other Military Fuels," Tech. rep., U.S. Army TARDEC, 2011. URL https: //apps.dtic.mil/dtic/tr/fulltext/u2/a554221.pdf, Report 22491.

[13] Heater, K., Bigg, D., Hodge, M., and Salee, G., "High Temperature, Long Service Life Fuel Cell Bladder Materials," Tech. rep., METSS Corporation, 2004. AFRL-ML-WP-TR-2004-4166.

[14] Atreya, S., Stoia, T., Mata, M., C., B., and O’Neil, P., "Fostering Ultra-Efficient, Low Emitting Aviation Power (FUELEAP) Final Report,” Tech. Rep. NASA NNL17AA45T BAART, Boeing Defense, Space, and Security Phantom Works, 2019. ITAR.

[15] Raymer, D. P., Aircraft Design: A Conceptual Approach, $2^{\text {nd }}$ ed., AIAA Education Series, 1992.

[16] Hoerner, S., Fluid-Dynamic Drag, Hoerner Fluid Dynamics, Brick Town, 1965.

[17] Jenkinson, L., Simpkin, P., and Rhodes, D., Civil Jet Aircraft Design, American Institute of Aeronautics and Astronautics, 1999.

[18] Norquist, D. L., "Fiscal Year (FY) 2019 Fuel Price Change," [Memorandum] Office of the Under Secretary of Defense, Sep. 2018. URL https://www.dla.mil/Portals/104/Documents/Energy/Standard\%20Prices/Petroleum\%20Prices/ E_PetroleumStandardPricesFY19_181001.pdf?ver=2018-10-01-131358-203.

[19] Leister, W., "Selected Acquisiton Report (SAR) MQ-9 Reaper Unmanned Aircraft System,” Tech. rep., Defense Acquisition Management Information Retrieval (DAMIR), 2016. RCS: DD-A\&T(Q\&A)823-424.

[20] Knee, D., "MQ-1B, MQ-9 flight hours hit 4 million," (article) USAF Air Combat Command Public Affairs, March 11, 2019. URL https://www . af.mil/News/Article-Display/Article/1781271/mq-1b-mq-9-flight-hours-hit-4million/, Accessed: 5/7/2019. 